\title{
A Comprehensive Review on Novel Liposomal Methodologies, Commercial Formulations, Clinical Trials and Patents
}

\author{
Veera Venkata Satya Naga Lakshmi Andra ${ }^{1}$ - S. V. N. Pammi ${ }^{2}$. Lakshmi Venkata Krishna Priya Bhatraju ${ }^{1}$. \\ Lakshmi Kalyani Ruddaraju'
}

Accepted: 12 January 2022 / Published online: 26 January 2022

(c) The Author(s), under exclusive licence to Springer Science+Business Media, LLC, part of Springer Nature 2022

\begin{abstract}
Liposomes are well-recognized and essential nano-sized drug delivery systems. Liposomes are phospholipid vesicles comprised of cell membrane components and have been employed as artificial cell models to mimic structure and functions of cells and are of immense use in various biological analyses. Liposomes acquire great advantages and provide wide range of applications as useful drug carriers in pre-clinical and clinical trials. This review summarizes exclusively on scalable techniques for liposome preparation and focuses on the strengths and limitations with respect to industrial applicability. Also, this review discusses the updated recent advancements in biomedical applications with a mention of key highlights of commercially available formulations, clinical trials and patents in recent past. Furthermore, this review also provides brief information of the classification, composition and characterization of liposomes.
\end{abstract}

Keywords Biological analysis $\cdot$ Drug delivery systems $\cdot$ Liposomes $\cdot$ Recent advancements

$\begin{array}{ll}\text { Abbreviations } & \\ \text { SUVs } & \text { Small unilamellar vesicles } \\ \text { LUVs } & \text { Large unilamellar vesicles } \\ \text { GUVs } & \text { Giant unilamellar vesicles } \\ \text { MLVs } & \text { Multi lamellar vesicles } \\ \text { OLVs } & \text { Oligo lamellar vesicles } \\ \text { MVVs } & \text { Multivesicular Vesicles } \\ \text { LMVs } & \text { Large multilamellar vesicles } \\ \text { SMVs } & \text { Small multilamellar vesicles } \\ \text { PEG } & \text { Polyethylene glycol } \\ \text { W/O emulsion } & \text { Water in oil emulsion } \\ \text { SCF } & \text { Super critical fluid } \\ \text { DAC } & \text { Dual asymmetric centrifugation } \\ \text { CAS } & \text { Continuous anti-solvent method } \\ \text { SRCPE } & \text { Supercritical CO } \text { reverse phase evapora- } \text { rever } \\ \text { RESS } & \text { tion process } \\ & \text { Rapid expansion of supercritical solution }\end{array}$

Lakshmi Kalyani Ruddaraju

lakshmikalyani.r@svcp.edu.in

1 Department of Pharmaceutical Sciences, Shri Vishnu College of Pharmacy, Vishnupur, Bhimavaram 534201, Andhra Pradesh, India

2 Department of Basic Sciences \& Humanities, GMR Institute of Technology (GMRIT), GMR Nagar, Rajam 532127, Andhra Pradesh, India
DELOS Depressurization of an expanded liquid organic solution suspension method

SAS Super critical anti-solvent

SEM Scanning electron microscopy

TEM

HPLC

HPTLC

Transmission electron microscopy

High-performance liquid chromatography

High-performance thin layer

chromatography

MRI Magnetic resonance imaging

DOX Doxycycline

VEGF Vascular endothelial growth factor

\section{Introduction}

Liposomes are spherical, closed structures composed of phospholipids in the colloidal size range of 5-200 nm and contains one or more concentric/non-concentric membranes, of around $4 \mathrm{~mm}$ thickness [1]. The liposomes consist of amphiphilic phospholipids with hydrophilic head and hydrophobic tail, which aids in unique characteristics such as self-sealing of liposomes in aqueous media. In recent past, much research has been focused on the delivery of antibiotics [2,3], genes [4, 5], antifungal [6,7], anti-inflammatory $[8,9]$ and anti-cancer drugs $[10,11]$ and also used in many pharmaceutical, biological and medical fields. 
In 1965, A.D. Bangham first discovered that phospholipid molecules can instantly form a closed bilayer vesicles in aqueous media due to amphiphilic nature of liposomes [12]. Shortly, liposomes in a size range of 5-200 $\mathrm{nm}$ have been noticed for encapsulation of hydrophilic or hydrophobic drugs into aqueous phase/bilayer membrane, which made a pavement of liposomes for drug delivery applications. Soon after first liposome-encapsulating drug reached clinical trials in 1985 [13], more than 40 liposome based formulations for drug delivery applications have been successfully entered into market from various clinical stages.

A significant advantage of systemic liposomes as drug formulations is high biocompatibility, low immunogenicity, biodegradability, increased efficiency, prolonged drug half-life, targeted delivery, lowered systemic toxicity and protection of sensitive molecules, with enhanced pharmacokinetics. The utmost advantage of systemic liposomes incorporation and release of two different materials with different solubility's simultaneously [14]. Reports from various investigations revealed different types of liposomes are classified based on number of bilayers, size and the liposomal composition and are discussed in further sections briefly.

Various publications are noted with focal point as conventional methods $[15,16]$, biomedical applications $[17,18]$ and recent advances in liposomal methodologies in liposomal [19]. In this review, we broadly focus on inventive ideas in methods of preparation and commercially available liposomal formulations with different routes of administration, characteristics and their applications to overcome the hindrances with conventional preparations. In addition, this review discusses in a broad range from conventional methods to recent advancements in preparation techniques and new innovation technologies in liposomal preparation along with mechanism of formation wherever possible with a mention of specific advantages and limitations of each liposomal methodology. Further, ongoing research on clinical trials and patents sanctioned in recent past is well detailed. Therefore, we anticipate this resource can give an overall pathway to choose an optimal method for the researchers with an up to-date knowledge on various bio medical applications with an idea on current research in clinical trials and patents to make a pavement for liposomes from the pre-clinical research to production and clinical use.

\section{Classification}

Liposomes classified into unilamellar, multilamellar, oligolamellar, and multi vesicular vesicles based on the number of phospholipid bilayers, as shown in Fig. 1. Various types of liposomes along with their particle sizes are given in Table 1. The desirable size of liposomes for drug delivery applications ranges from 50 to $200 \mathrm{~nm}$ [20, 21].

Liposome size is the major factor for efficient delivery of drugs into the body. The size of liposomes shows significant effect on the pharmacokinetics of liposomes and drugs encapsulated into the liposomes. The size of liposomes less than $200 \mathrm{~nm}$ shows increased circulation and residence time of liposomes in the blood, enhanced in vivo drug release from liposomes and significant accumulation into the tumour cells [22].

\section{Composition of Liposomes}

\subsection{Phospholipids}

Liposomes are comprised of lipid and/or phospholipid molecules with different head groups and minimal amounts of other additives which should be incorporated in an internal aqueous core and an outer lipid bilayer. Phospholipids are amphiphilic molecules, with a hydrophilic phospholipid head and a hydrophobic fatty acid tail. Phospholipids possess glycerophospholipids and sphingomyelins.

Table 1 Types of liposomes and their particle size

\begin{tabular}{lll}
\hline Types of liposomes & Particle size & $\begin{array}{l}\text { Number } \\
\text { of lamel- } \\
\text { lae }\end{array}$ \\
\hline Small unilamellar vesicles [SUVs] & $20-100 \mathrm{~nm}$ & 1 \\
Large unilamellar vesicles [LUVs] & $>100 \mathrm{~nm}$ & 1 \\
Giant unilamellar vesicles [GUVs] & $>1000 \mathrm{~nm}$ & 1 \\
Multi lamellar vesicles [MLVs] & $>500 \mathrm{~nm}$ & $>5$ \\
Oligo lamellar vesicles [OLVs] & $100-1000 \mathrm{~nm}$ & $2-5$ \\
Multi vesicular vesicles [MVVs] & $>1000 \mathrm{~nm}$ & 1 \\
\hline
\end{tabular}

Fig. 1 Classification of liposomes

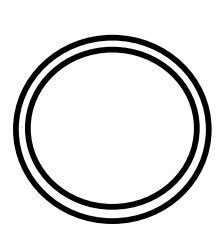

SUV

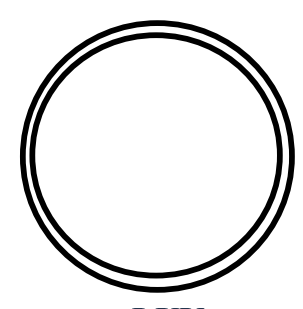

LUV

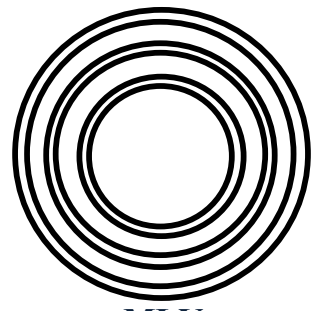

MLV

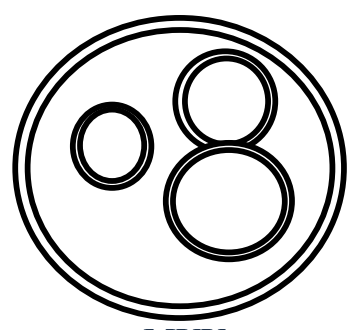

MVV 
Glycerophospholipids consists a lipophobic head and a lipophilic tail. Different substitutions at head groups such as phosphatidylcholine, phosphatidylinositol, phosphatidylserine, phosphatidylethanolamine, phosphatidic acid, cardiolipin, and phosphatidylglycerol result in various glycerophospholipids [23]. Furthermore, the variation in length of the nonpolar moieties produces different glycerophospholipids, such as dipalmitoyl, dimyristoyl, or distearoylphosphatidylcholine. Additionally, the type of bonding, i.e. ether or ester between glycerol and aliphatic chains, provides various types of glycerophospholipids. To achieve charged vesicles, charged phospholipids like stearyl amine and diethylphosphate can been used. Binding of sphingomyelin helps in water permeability reduction and enhancement of proton permeability in some kinds of liposomes [24]. Lipids are capable to manipulate the surface charge, bio distribution, permeability, release and clearance of various formulations of liposomes [25]. The segments of phospholipids govern the encapsulation efficiency, stability and toxicity of liposomal formulations [26].

\subsection{Bilayer Excipients}

Phospholipids alone are usually inadequate for the preparation of liposomes, which might trigger defects in the bilayer packing leading to outflow of captured drug due to unsaturation of fatty alkyl chains or low phase transition temperature during storage. In order to avoid such outflow, various other bilayer excipients are added to the liposome composition. Cholesterol and $\alpha$-tocopherol are the most widely used excipients [27]. Modifications in the phospholipid bilayer composition influence the liposome encapsulation efficiency. The aggregates formed by electrostatic effect and the fluidity of phospholipid bilayers can be stabilized by using cholesterol. The variation in the quantity of cholesterol used in the liposome preparation is based upon the area of liposome application. On the other side, $\alpha$-tocopherol affords for higher therapeutic potential through inducing reactive oxygen species in injured tissue, thereby liposomes readily ease the intracellular delivery and prolong the retention time of encapsulated drugs [28].

\subsection{Additional Excipients}

Polyethylene glycol [PEG] on the liposome surface offers extended circulation property, protects the captured drug from inactivation or metabolic degradation, further enhances stability and improves intracellular intake [29]. PEG may produce stealth liposomes that are undetectable by the body's reticuloendothelial system [30, 31]. Moreover, PEG assists in decreasing particle's aggregation and improves the stability on storage [32]. Cellular intake of PEGylated liposomes can be enhanced by ligands such as antibodies, vitamins, proteins and nucleic acids, which exists on the receptor surface of target cells.

Research on liposomal technologies was continuously refined from conventional vesicles to "second-generation liposomes", i.e. the extended-circulating liposomes with controlled and gradual release of active pharmaceutical ingredient, which can be achieved by modifying the phospholipid composition, dimension and charge of the vesicle. Numerous particles like sialic acid or glycolipids [15, 33], unmodified dextrans and modified dextrans are used to establish the modified surface liposomes [34].

\section{Liposome-Based Carrier System}

Liposomes are the drug carriers which are capable to carry the drugs into specific target sites [16], and different carrierbased systems are listed in Table 2.

\section{Methods of Preparation}

Liposome preparation can be done by conventional methods such as Bangham method [thin film hydration], ether/ethanol injection method, reverse phase evaporation method, detergent depletion method, heating method, microfluidic channel method, membrane extrusion method, homogenization and sonication method. Novel methods for liposomal-based drug delivery involve freeze drying, dual asymmetric centrifugation $[\mathrm{DAC}]$ and supercritical fluid $[\mathrm{SCF}]$ methods since a decade [46]. Depo-foam liposome technique, lysolipid thermally sensitive liposome technique, non-PEGylated liposome technique and stealth liposome techniques are the innovative techniques used for the delivery of drugs in the recent past, and each method and its status are discussed further.

\subsection{Conventional Methods}

\subsubsection{Thin Film Hydration Method [Bangham Method]}

The Bangham method is the first commonly used method for liposome preparation $[12,47]$. This method utilizes an organic solvent (dichloromethane, chloroform, ethanol and chloroform-methanol mixture) to dissolve lipids; further the organic solvent can be removed by evaporation under vacuum at a temperature of $45-60^{\circ} \mathrm{C}$ to form a thin lipid film. Subsequently, the thin lipid film gets hydrated in aqueous media by continuous agitation up to $2 \mathrm{~h}$ at a temperature of $60-70^{\circ} \mathrm{C}$ where it swells to produce round closed liposomes [48]. The schematic representation of Bangham method is represented in Fig. 2.

\section{Advantages:}


Table 2 Different liposome carrier-based systems

\begin{tabular}{ll}
\hline Vesicle type & Characteristics \\
\hline Immunoliposomes & - Aids in targeting the bioactive agents inside the body [35] \\
Virosomes or artificial viruses & • Composed of reconstituted viral proteins structurally [36] \\
Stealth liposomes & - Carrier surface covered with hydrophilic chains [PEG] \\
& - Bypasses phagocytosis and aids in longer circulation in the blood [37, 38] \\
Archaeosomes & - Composed of one or more ether lipids [polar] isolated from Archaebacteria [39] \\
& - These are highly thermostable and resistant to oxidation, chemical and enzymatic hydrolysis. They are highly \\
& - These are cigar-shaped multi-layered structure, which consist of negatively charged lipid molecule such as \\
Cochleates & phosphatidylserine and a divalent cation. Cochleates can deliver positively or negatively charged molecules, \\
& which can be hydrophobic or amphiphilic. Opted for systemic and oral delivery of sensitive moieties espe- \\
& cially antioxidants [42, 43] \\
- These are highly concentrated dispersions of phospholipids and are of semisolid consistency with vesicles & - Used as parenteral depot formulations for drugs with poor storage stabilities and more leakage rates [44] \\
Vesicular phospholipid gels & - Longer circulation time in the blood stream and easy penetration into tissues with sustaining effect for days \\
Nano liposomes & Employed for encapsulation and delivery of both vitamin E and ascorbic acid at the oxidation site in the food \\
& system [45]
\end{tabular}

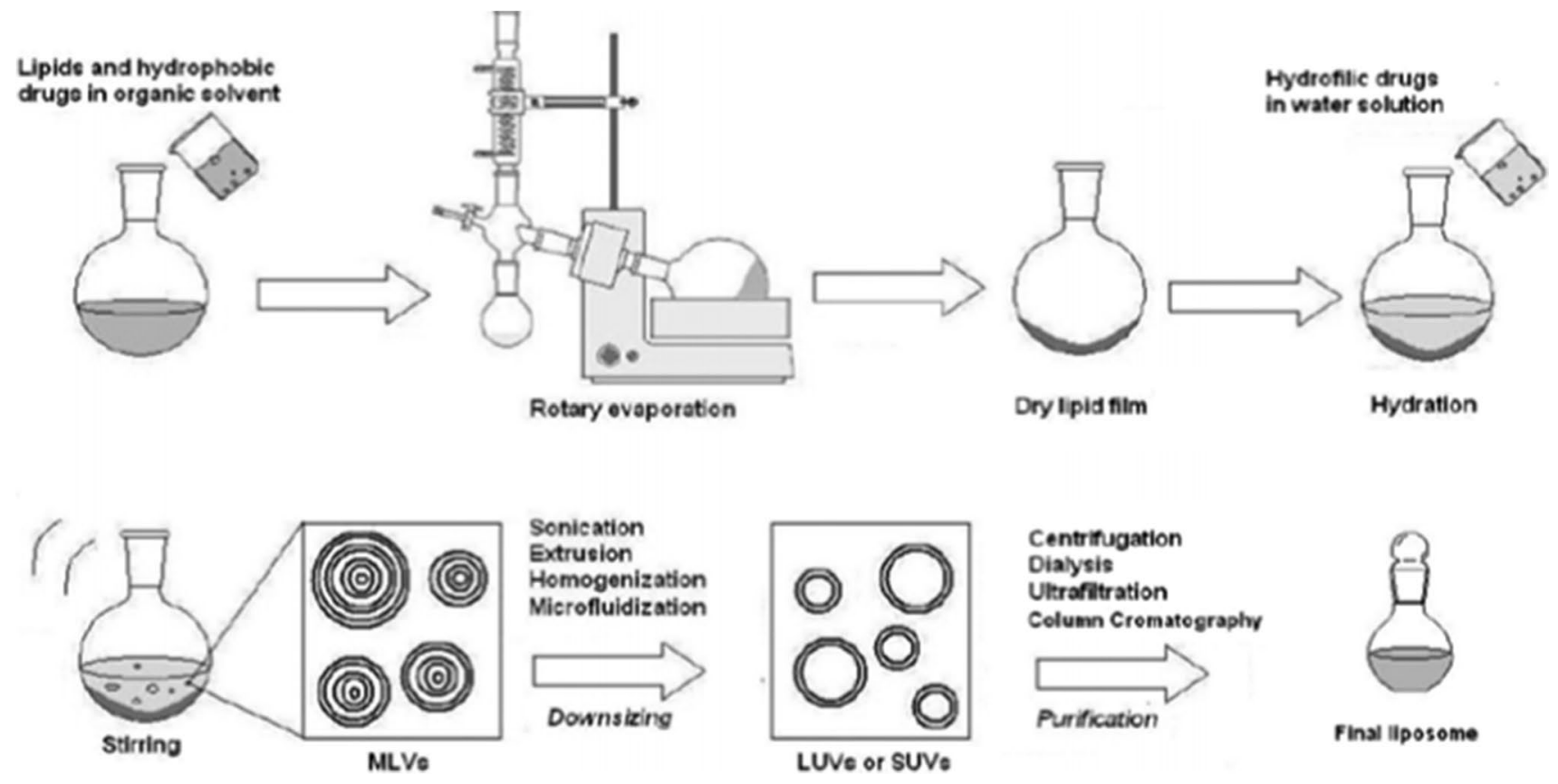

Fig. 2 Schematic representation of Bangham method, adapted from [49]

- Simple process

- Straightforward approach

- Used for all kinds of lipid mixtures

Disadvantages:

- Water soluble drugs exhibit low entrapment efficiency.

- Difficulty in scaling up.

- Removal of organic solvent is troublesome.

- Large vesicles without particle size control.

- Time-consuming method.

- Sterilization is needed.

\subsubsection{Ethanol/Ether Injection Methods}

Batzri and Korninitially described the ethanol injection method in 1973 [50]. In both ethanol and ether injection methods, lipids should be dissolved in an organic solvent (diethyl ether or ether-methanol mixture or ethanol), followed by injection of mixed solution into aqueous phase, where the material should be encapsulated at $55-65^{\circ} \mathrm{C}$ or under reduced pressure to attain liposomes. Further, as ether is immiscible with aqueous media, heating is necessary to 
evaporate organic solvent from the prepared liposomes [51]. Hauschild et al. developed the inkjet method as the modern method of ethanol injection; in this method the drug solution that is hydrophilic/lipophilic or both was dissolved in ethanol and transformed to inkjet device for the preparation of liposomes with tremendous control on particle size and for large-scale production [52].

\section{Advantages}

- Ethanol injection method is simple, rapid, reproducible and ready to use.

- Ether injection method forms a concentrated liposome product with greater entrapment efficiency.

\section{Disadvantage}

- Improper mixing may produce heterogeneous liposomes.

- Removal of ethanol is difficult because it forms azeotrope with water.

- Various biologically active macromolecules are inactive in presence of even low amounts of ethanol.

- Possible nozzle blockage (ether system).

\subsection{Reverse Phase Evaporation Method}

Szoka and Papahadjopoulos initially described the reverse phase evaporation method [53], where lipids are dissolved in an organic solvent and desired drugs are dissolved in an aqueous media; further the mixture is sonicated to produce w/o emulsion or inverted micelles, followed by slow removal of organic solvent using rotary evaporator, leading to conversion of these micelles into viscous state or gel product. In this process, at a critical point, the gel state collapses and some inverted micelles were distributed. The excess phospholipids form the bilayer around the residual micelles which results in the formation of liposomes. Modified reverse phase evaporation method was presented by Handa et al., and the main advantage of this method is the liposome which had high encapsulation efficacy (about 80\%) [54].

\section{Advantages}

- Simple process

- Suitable encapsulation efficacy

- Used to encapsulate small, large and macromolecules

\section{Disadvantages}

- Use of large quantity of organic solvent.

- Unfit to carry and deliver fragile molecules such as peptides.

- Time-consuming method.

- Sterilization is required.

\subsubsection{Detergent Depletion Method}

This technique is used to manufacture homogeneous liposomes for various drug delivery applications. This method determines the solubility of lipid by addition of proper detergent in an organic solvent at their critical micelle concentration to produce detergent lipid micelles. Once after the detergent is removed, the micelles become increasingly better-off in phospholipid and finally combine to form liposomes [55]. Detergents should be removed by dialysis. A commercial device called LipoPrep is used for the elimination of detergents. The dialysis was performed in dialysis bags placed in large detergent-free buffers (equilibrium dialysis) [56]. Size and uniformity of liposomes by detergent method depend on the rate and extent of detergent removal and on phospholipid to detergent ratio.

\section{Advantages}

- Good particle size control

- Simple process

- Homogenous product

\section{Disadvantages}

- Low concentration of liposomes in the ultimate solution

- Low entrapment of lipophilic drug

- Time consuming process

- Removes minute water soluble compounds during removal of detergent

\subsubsection{Microfluidic Channel Method}

Microfluidic method was established by Jahn et al. [57], for controlled liposome preparation. In this method, lipids are dissolved in isopropyl alcohol, which then passes through the centre of the dual channels containing aqueous media. The stream of the lipids in isopropyl alcohol was subsequently mixing forming liposomes. Size and size distribution of liposomes are controlled by laminar flow and lipid concentrations in microfluidic channels. This is an effective method to encapsulate the drug directly to attain self-assembled liposomes [58].

\section{Advantages}

- Simple method

- Good particle size control

- Low-cost method

Disadvantages

- Difficulty in removal of organic solvent

- Unsuitable for bulk production 


\subsubsection{Heating Method}

Mortazavi and Mozafari developed the heating method to acquire liposomes [59]. In this method, the phospholipids are hydrated with the help of glycerol, PEG/ethylene glycol with continuous stirring for $1 \mathrm{~h}$ at $60^{\circ}$ or $120^{\circ} \mathrm{C}$. After cooling, mixture must be centrifuged at $4000 \mathrm{rpm}$ for $15 \mathrm{~min}$ to obtain the liposomes. Liposomes produced by this method do not suffer from deterioration of phospholipids, and sterilization is not mandatory as this process involves high temperature, i.e. $120^{\circ} \mathrm{C}$ [60]. Additionally, Mozafari method is the upgraded method of heating method, in which the lipid components are hydrated in aqueous media followed by heating of components without using of organic solvents; here stability is increased and used for the delivery of flavourzyme [de-bittering agent] [61].

\section{Advantage}

- Simple and fast process.

- Non-contamination (e.g. organic solvent).

- Sterilization is not needed.

\section{Disadvantages}

- Low encapsulation efficacy

- Requires high temperature

- Possible degradation of phospholipids and drugs

\subsubsection{Membrane Extrusion Method}

This method is widely used for the conversion of MLVs into SUVs and LUVs. The liposomes size should be decreased by passing them through the polycarbonate membrane filter having specific pore size at low pressure $(<100 \mathrm{psi})$. Before extrusion, LMV are disrupted by freeze-thaw cycles/prefiltering through large pore size $0.2-1 \mu \mathrm{m}$.

In this process, the vesicle contents are extruded several times with the dispersion medium during the breaking and resealing of phospholipids layers as they pass through the polycarbonate membrane. The mean size of vesicles obtained by extrusion decreases with increase in the transmembrane pressure as well as the number of extrusion cycles. The formed liposomes are called as large unilamellar vesicles by extrusion having particle size of $120-140 \mathrm{~nm}$ [62].

\section{Advantages}

- Simple and fast process

- Good particle size control

- Non-contamination (e.g. organic solvent)

- Several membrane/filter pore sizes available for producing liposomes

\section{Disadvantages}

- Not suitable for large-scale processing

- Possibility of clogging the pores

- Limitation in large-scale production

- Membrane/filter fragility

- Slow flow through the membrane/filter

\subsubsection{High Shear Homogenization}

Homogenization is widely used for the liposomes size reduction and lamellarity. During homogenization the liposome suspension is continuously pumped through an orifice, and at very high pressure, it collides with a stainless steel wall in the homogenizer system to produce less size liposomes.

\section{Advantages}

- Suitable for large-scale production

- Good particles size control

\section{Disadvantages}

- Liposome size distribution is quite broad and variable.

- Possible metal and oil contamination.

- Use of very high pressure.

\subsubsection{Sonication}

Sonication method is widely used for the preparation of SUVs. There are 2 sonication techniques used to sonicate MLVs, namely, bath type sonicator or a probe sonicator under substantial atmosphere [15].

a) Probe sonication: The sonicator tip is directly dipped into the liposome dispersion. The energy input into lipid dispersion is very high, and the coupling energy at the tip leads to heating. Thus, the vessel should be placed into a water/ice bath throughout the sonication process up to $1 \mathrm{~h}$. More than $5 \%$ of lipids can be de-esterified and titanium may pollute the solution.

b) Bath sonication: Liposome dispersion is taken in a cylinder and is placed into a bath sonicator. In this the temperature should be controlled in contrast to probe sonication. The material being sonicated can be protected in a sterile vessel under inert atmosphere.

\section{Advantages}

- Simple process.

- Particle size is controlled.

\section{Disadvantages}

- Very low encapsulation efficacy/internal volume

- Possible degradation of phospholipids and compounds 
- Elimination of large molecules

- Metal pollution from probe sonicator

- Presence of MLVs along with SUVs

Conventional methods used in the preparation of liposomes have several limitations like low mono-dispersibility, reduced stability, high organic solvent residue and toxic effects. Additionally, the organic solvents used in traditional method affect the environment, produce toxicity for human health and often degrade the drug. The use of organic solvents/detergents in preparation of liposomes may lead to protein/drug denaturation and affects membrane property [2].

\subsection{Novel Methods}

To overcome the stability and formulation issues with conventional methods, numerous innovations in methodology have taken place, and they are described in further sections, and liposomes prepared by using various novel techniques are presented in Table 3.

\subsubsection{Freeze Drying Method}

Liu et al. discovered lyophilization monophasic solution technique for the preparation of liposomes. This method involves dissolving of lipid and drug in tert-butyl alcohol at $45^{\circ} \mathrm{C}$, and lyo-protectant dissolves in water at $45^{\circ} \mathrm{C}$. Both of the obtained solutions are mixed to form third identical monophasic solution, followed by filtration, and freeze drying of solution is performed to produce proliposomes. Freeze drying involves 2 steps: in first, the sample is frozen at $-40^{\circ} \mathrm{C}$ and then dried at room temperature which upon hydration eventually forms liposomes with mean dimension of 100-300 nm [76].

\section{Advantages}

- Single step method

- Used for commercial scale production

- Increases the shelf-life of the liposomes

- Prevents the physical degradation of liposomes during storage

\section{Disadvantages}

- It is a time and energy consuming process

- May induce physical alterations, i.e. alterations in vesicle size

- Loss of encapsulated material can occur

\subsubsection{Dual Asymmetric Centrifugation Method (DAC)}

DAC is a unique centrifugation method in which sealed vials are rotated on the main rotational axis with a definite speed

Table 3 Novel preparation methods with examples

\begin{tabular}{|c|c|c|c|c|c|c|}
\hline Method & Type of vesicles & Particle size & Drug type & $\mathrm{EE}$ & Example & Reference \\
\hline Reverse phase evaporation & $\begin{array}{l}\text { MLVs } \\
\text { LUVs }\end{array}$ & $>500 \mathrm{~nm}$ & Hydrophilic & $30-50 \%$ & Spirulina LEB-18 & {$[63]$} \\
\hline Ethanol/ether injection & $\begin{array}{l}\text { SUVs, SMVs } \\
\text { MLVs }\end{array}$ & $>100 \mathrm{~nm}$ & Lipophilic and hydrophilic & $99 \%$ & Beclomethasone dipropionate & [64] \\
\hline Heating method & GUVs & $>1000 \mathrm{~nm}$ & Lipophilic & $30-49 \%$ & Flavourzyme & {$[62]$} \\
\hline Thin film hydration & GUVs & $>1000 \mathrm{~nm}$ & Lipophilic & $67 \%$ & Dexamethasone & {$[65]$} \\
\hline Freeze drying & SUVs & $<200 \mathrm{~nm}$ & Lipophilic & $87-93 \%$ & $\begin{array}{l}\text { Calcein, flubiprofen } \\
\text { Amphotericin B }\end{array}$ & [66] \\
\hline Membrane contractor & SUVs, LUVs & $100 \mathrm{~nm}$ & Lipophilic & $71 \%$ & Spironolactone & {$[67]$} \\
\hline $\begin{array}{l}\text { Dual asymmetric centrifuga- } \\
\text { tion }\end{array}$ & LUVs & $70-120 \mathrm{~nm}$ & Hydrophilic & $80 \%$ & SiRNA-Liposomes & {$[68]$} \\
\hline \multicolumn{7}{|l|}{ Super critical fluid technology } \\
\hline - SAS & & & & $100 \%$ & Vitamin D3 liposomes(VDL) & [69] \\
\hline - RESS & & & & $78.38 \%$ & Vitamin C & {$[70]$} \\
\hline - DELOS & & & & $52.2 \%$ & Anthocyanin & [71] \\
\hline - Super Lip & & & & $98 \%$ & Theophylline & {$[72]$} \\
\hline - SCRPE & MLVs & $100-200 \mathrm{~nm}$ & Hydrophilic and lipophilic & $40 \%$ & $\begin{array}{l}\text { D- }(+) \text { Glucose } \\
\text { Lavandin essential oil }\end{array}$ & [73] \\
\hline - PGSS & & & & $6-14 \%$ & $\begin{array}{l}\text { L- } \alpha-D P P C \text { and chitosan/ } \\
\mathrm{D}-(+)\end{array}$ & [74] \\
\hline $\begin{array}{l}\text { - ISCRPE (improved } \\
\text { SCRPE) }\end{array}$ & & & & $17 \%$ & GLUCOSE & {$[75]$} \\
\hline
\end{tabular}


and distance as well as it rotates on its own axis, while in general centrifugation process, the vials should be rotated on its own centre axis. The main rotation pushes the sample into outward direction and rotation around the own centre pushes the sample material into opposite direction due to adhesion between the sample and rotating vial. Thus, energy reaches into the sample preparation by mechanical turbulence and capitations to produce nano-liposomes with a size of about $60 \mathrm{~nm}$ for ideal size distribution [66].

\section{Advantages}

- Equipment is small in size and easy to operate.

- Reproducibility.

- Produce liposomes with small particle size.

- Water-soluble drugs have high entrapment efficiency.

- No organic solvents are used.

\section{Disadvantages}

- Needs high amount of phospholipids to obtain sufficient viscosity.

- Batch scale production.

\subsubsection{Supercritical Fluid Methods (SCF)}

To overcome the limitations of toxicity and degradability of conventional methods, SCF methods are developed as green techniques which involves supercritical anti-solvent method (SAS), supercritical reverse phase evaporation method (SCRPE), depressurization of an expanded liquid organic solution-suspension method (DELOS), supercritical assisted atomization, supercritical assisted liposome formation (super Lip) [68], supercritical fluid extraction and particles from gas saturated solutions as a popular alternative methods for conventional methods of liposomal preparations $[77,78] . \mathrm{CO}_{2}$ is the commonly used supercritical gas, because it is inflammable, cheap, non-corrosive, non-toxic, environmental friendly and used for thermolabile substances [79].

Supercritical Anti-solvent [SAS] Method It is widely used method for the preparation of proliposomes. SAS is the best method as it offers simple approach, contains low solvent residue and is used for the drugs with low solubility in the SCFs (antisolvent) [80]. In this method, supercritical fluid is passed from the top through the high pressure chamber, and then the drug solution is sprayed on the SCF as small droplets by using atomized nozzle. The liposomes are attained when hydrated with aqueous solution. The supercritical $\mathrm{CO}_{2}$ acts as antisolvent to the solute but it is miscible with organic solvent. The liposomes obtained are free from organic solvent when compared to liposomes produced by conventional method. The upgraded method of SAS is called as "Continuous Anti-Solvent (CAS)" method.

CAS involves two procedures: CAS1 is a single exit process, and in this, liposome solution was injected into an autoclave, and then $\mathrm{CO}_{2}$ was filled and organic solution was sprayed under continuous stirring of liposomal solution. The $\mathrm{CO}_{2}$ and liposome suspension was recovered from the same valve. CAS2 is a two exit process; in this liposomal suspension is extracted from bottom of the autoclave and $\mathrm{CO}_{2}$ from top of the autoclave [81].

\section{Advantages}

- Contains low solvent residue.

- Used for the drugs with low solubility.

- Efficient and environmentally friendly process.

- Particle size is controlled and repeatable.

\section{Disadvantages}

- Causes agglomeration and aggregation of particles.

- Presence of residual toxic solvents in the final product.

Supercritical $\mathrm{CO}_{2}$ Reverse Phase Evaporation Process [SCRPE] The SCRPE method was developed by Otake et al. [82]. In SCRPE method, the lipid, organic co-solvent and compressed gas are combined in a stirred variable volume cell at a temperature above the lipid phase transition temperature at $60^{\circ} \mathrm{C}$ and $10-30$ bar. An aqueous solution is then slowly introduced to the cell, and the pressure is reduced by the release of the compressed gas to attain liposomes with the mean diameter of 200-1200 $\mathrm{nm}$. With the decreasing lipid concentration, the mean size decreases to $100-250 \mathrm{~nm}$. The principle of the SCRPE method is similar to the decompression method. Otake et al. recently developed a new method known as the improved supercritical reverse phase evaporation [ISCRPE] technique in which phospholipid and drug were sealed in view cell and then temperature raised to $60^{\circ} \mathrm{C}$, and $\mathrm{CO}_{2}$ was passed for $40 \mathrm{~min}$, and the pressure is released to get liposome dispersion [83].

\section{Advantages}

- Free from organic solvents.

- Can encapsulate both water soluble and oil soluble materials.

- Used for commercial scale production.

- Less time-consuming.

\section{Disadvantages}

- Low encapsulation efficiency

- Low liposome stability 
Rapid Expansion of Supercritical Solution [RESS] Method RESS process is advantageous to achieve micronization of poorly water-soluble drug. The important parameters to be considered in RESS are drug solubility in SCF as it effects the super saturation and particle size distribution. This process is carried out in two steps: (a) dissolving the solid substances in the supercritical fluid and (b) formation of particles by super saturation. Initially, supercritical fluid is passed through the extractor at required temperature and pressure. Then SCF penetrates and dissolves the solid substances in the extractor at low-pressure chamber, where the solution is depressurized by using a heated nozzle. Additionally, cooling by this RESS method may involve nozzle block and cause particle de-aggregation [75].

\section{Advantages}

- Simple and effective process

- Reduces the use of organic solvents and can be reused

\section{Disadvantages}

- Poor solubility of the polymeric materials in supercritical $\mathrm{CO}_{2}$.

- Huge volume of fluid is needed.

- Expensive.

- May involve nozzle block.

Depressurization of an Expanded Liquid Organic Solution Suspension Method [DELOS] In this method, the phospholipids are dissolved in organic solvent at required temperature and pressure, and then the solution is added and mixed with the supercritical $\mathrm{CO}_{2}$ in a vessel which acts as a cosolvent. Further, this solution is depressurized by using a nozzle to produce liposomes. The advantage of this method when compared to PGSS method is thermo-sensitive materials can be used to prepare liposomes, as this process does not require high temperature and this process is carried out under slight working pressure [i.e. $10 \mathrm{MPa}$ at $35^{\circ} \mathrm{C}$ ] [70].

Advantages

- Simplicity in methodology

- Works under slight conditions

- Used for thermo-sensitive materials

\section{Disadvantages}

- Presence of residual organic solvent

- Nozzle blockage

Super-Critical Assisted Liposome Formation [Super Lip] For liposome formation through super lip, as a prime step, the lipid dissolves in ethanol and then mixed with pure $\mathrm{CO}_{2}$ in a saturator to get an expanded fluid. The saturator is packed with baffles and kept at high pressure; further thin bands are heated thermally to produce SCF. Then the mixture was passed through the high-pressure formation vessel, and then aqueous solution containing drug was atomized. The working temperature of the saturator and the formation vessel was set to $40{ }^{\circ} \mathrm{C}$ and pressure at 100 bar. From the bottom of the vessel, the liposome suspension was collected, and $\mathrm{CO}_{2}$ and ethanol were separated by using a stainless steel separator which is maintained at $30{ }^{\circ} \mathrm{C}$ and 10 bar pressure. The encapsulation efficiency is dependent on the flow rate of the aqueous solution, and increased flow rate leads to decreased entrapment efficiency [84, 85].

\section{Advantages}

- Process is continuous and replicable.

- Used to encapsulate hydrophilic drugs.

- High entrapment efficiency.

- Low solvent residue.

\section{Disadvantages}

- Time-consuming process

- Requires high pressure

\section{Types of Drug Loading in Liposomes}

Main problem associated with liposomes for drug delivery applications is drug loading (hydrophilic/hydrophobic). Most importantly, in a multistep preparation, it is very important to distinguish when the drug is to be incorporated and at what stage into the system. There are two types of drug loading for drug delivery through liposomes, i.e. passive loading and active loading technique.

Passive loading technique involves the lipid films placed on a substrate followed by hydration to form liposomes. In active loading technique, the drug is incorporated after the liposome preparation. Mostly, they are the gradient loading techniques that use buffer ammonium sulphate as gradients. For active loading of weak base (e.g. ammonium sulphate) into liposomes, trans-membrane gradient is used as driving force. For proper loading of weak base with $\mathrm{pKa}$, less than 11 and $\log \mathrm{P}$ values from -2.5 to 2 can be used [73].

\section{Characterization of Liposomes}

\subsection{Size and Size Distribution}

The vesicle size is crucial to determine the in vivo release of drug-loaded liposomes. The average size of liposomes depends on the method of preparation and phospholipid 
composition. Various methods are used to evaluate the size and size distribution such as:

(1) Microscopic techniques such as optical microscopy, scanning electron microscopy (SEM), negative stain TEM and freeze-fracture TEM. SEM and TEM techniques are used for imaging of liposomes and also provide information about bilayer thickness and inter-bilayer distance of liposome [74]. One of the newly established microscopic methods is atomic force microscopy (AFM), which is a very high-resolution scanning probe microscopy that produce $3 \mathrm{D}$ micrographs through resolution of nano-meter and $\mathrm{A}^{0}$ scale to evaluate the liposome morphology, stability, size and dynamic process of lipid nano-capsules [86]. (2) Hydrodynamic techniques such as ultracentrifugation, field flow fractionation and gel exclusion chromatography and analytical centrifugation procedures are used to estimate molecular mass of compound and also used for comparison of size distribution, elution characteristics and uniformity of the liposomes [87].

(3) Diffraction light scattering techniques such as laser light scattering, quasi-elastic light scattering and photon correlation spectroscopy give information about the size of the lipid vesicles.

The mean diameter of $<1 \mu \mathrm{m}$ liposomes can be estimated by using these techniques. The liposomes size must be monitored for different liposome preparations based on use for parenteral applications, topical use and inhalation purpose. For controlling of the liposomal size, numerous procedures such as sonication, extrusion and homogenization are available.

\subsection{Lamellarity Determination}

Lamellarity is defined as the number of lipid bilayers present around the lipid vesicles. Liposomal lamellarity can be measured by using cryo-electron microscopy, 31P-nuclear magnetic resonance (NMR) and small angle X-ray scattering (SAXS) technique that provide information about size, homogeneity and lamellarity of liposomes [88].

\subsection{Zeta Potential}

The zeta potential is the key factor that affects the cellular uptake and targeted drug delivery. The laser Doppler electrophoresis and Zetasizer are used to measure the zeta potential of the liposomal dispersion by applying an electric field based on the scattering of incident laser on the moving particles. There are several factors which influence the zeta potential such as $\mathrm{pH}$, ionic strength and particle concentration. Lipid composition, i.e. positive- and negative-charged phospholipids in liposome influences overall surface charge and blood circulation time of liposomes [89].

\subsection{Encapsulation Efficiency/Entrapment Efficiency}

Encapsulation efficiency is defined as the percentage of aqueous phase and percentage of water soluble drug entrapped during preparation of liposomes. It should be expressed as \% entrapment/mg of lipid. Enhancing entrapment efficiency will increase the drug bioavailability [90]. Various methods such as solid phase extraction, size exclusion chromatography, hollow fibre-centrifugal ultrafiltration and centrifugation ultrafiltration, mini-column centrifugation and protamine aggregation methods are used to measure the entrapment efficiency. Mini-column centrifugation method is used for purification and separation of liposomes, and protamine aggregation method is used for neutral and negatively charged liposomes.

Indirect method used to measure the encapsulation efficiency is the amount of un-encapsulated drug value that should be deducted from the total quantity of the drug to be used [91].

\subsection{In vitro Drug Release Studies}

The in vitro drug release studies are assessed at $37^{\circ} \mathrm{C}$ through in vitro diffusion cell or by using dialysis bag. The cell or bag must be wet through receptor medium containing $\mathrm{pH} 7.4$ buffer with constant stirring under sink conditions, which mimics the in vivo conditions. At regular time intervals, the required volume of the medium was collected, and the concentration was determined by using HPLC and UV-Visible spectrophotometry, and at the same time equal volume of fresh medium was added to receptor media. The cholesterol concentration in liposomal formulations will affect the release of water soluble drugs, and as the concentration of cholesterol increases, it enhances the release rate of the drug [92].

\subsection{In vivo Performance}

The in vivo behaviour of drug-loaded liposomes might be influenced by several pharmacokinetic properties of the vesicle. To study the in vivo performance of liposomal drug delivery systems, the liposomes are administered intravenously to reveal rapid clearance from spleen and liver. The large liposomes having particle size greater than $0.5 \mu \mathrm{m}$ diameter taken by phagocytosis and for liposomes having particle size less than $0.1 \mu \mathrm{m}$ were taken up by liver parenchymal cells. Cholesterol incorporated in liposomes will increase stability by evading the leakage of drug.

Recently imatinib (anticancer drug)-loaded magnetic liposome nano-composites were synthesized, which was 
functionalized with hyaluronic acid. In vivo behaviour of this magnetic liposomes is evaluated by tail vein injection in a mice model, and the fluorescent images were taken at 2, 4, and $8 \mathrm{~h}$ after injection. The uptake/retention of magnetic liposomes takes place at maximum fluorescence signal after $4 \mathrm{~h}$ [93].

\subsection{Stability Studies}

The stability studies are used to determine the shelf life of liposomes that involves physical stability, chemical stability, and biological stability. In physical stability, colour change of liposomes can be observed visually or by using TEM and AFM. Chemical stability involves hydrolysis, oxidation and drug degradation that can be determined by using HPLC, TLC and HPTLC and thiobarbituric acid (TBA) test.

\section{Commercially Available Liposomal Formulations}

The commercially available formulations of liposomal drug delivery systems prepared through different methods used for specific purposes are listed in Table 4.

\section{Applications of Liposomes}

\subsection{In Ophthalmic Disorders}

Various drugs are used to treat eye disorders, i.e. dry eyes, keratitis and corneal transplant rejection, which should be applied topically via ointment, solution and suspension form. Due to several barriers present in the eye, these preparations exhibit poor ocular bioavailability. To avoid this hindrance, liposome formulations are used. In the treatment of dry eyes, the liposome suspension and a spray which deliver the drugs into conjunctival sac are investigated and developed.

The ciprofloxacin/ciprocin is the most widely used eye drops which is effective against gram +ve and gram -ve bacteria. Here, on comparison of ciprocin eye drops with ciprocin liposome preparations in rabbits, the area under the curve values for liposome preparations are high causing enhanced ocular bio-availability, residence time and low dose when compared to ciprofloxacin eye drops [94].

\subsection{In Cancer Chemotherapy}

There is a vast difference between the nature and function of cancer cell with the normal one, and the cancer cell has enhanced permeation rate effect. The tumour has highly permeable nature, and so the micro and macromolecules can easily enter into various tumour cells. Also, specific bio-markers

Table 4 Commercially available liposome formulations

\begin{tabular}{|c|c|c|c|c|}
\hline Disease & Drug & Route of administration & Method of preparation & Improved profile \\
\hline Fungal infection & Amphotericin B & I.V infusion & Conventional method & $\begin{array}{l}\text { Low toxicity, improved } \\
\text { bilayer stability }\end{array}$ \\
\hline Breast neoplasms & Doxorubicin & I.V injection & Stealth liposome technology & $\begin{array}{l}\text { Tumour targeting, high } \\
\text { stability }\end{array}$ \\
\hline Analgesic & Morphine sulphate & Epidural & Depofoam technology & $\begin{array}{l}\text { Prolonged analgesia with low } \\
\text { adverse effects }\end{array}$ \\
\hline Viral vaccines & Hepatitis A & IM/SC injection & Detergent removal technique & Inactivation of influenza virus \\
\hline Cancer therapy & $\begin{array}{l}\text { Daunorubicin } \\
\text { Cytarabin }\end{array}$ & $\begin{array}{l}\text { I.V injection } \\
\text { I.V injection }\end{array}$ & $\begin{array}{l}\text { Conventional method } \\
\text { Depofoam technology }\end{array}$ & $\begin{array}{l}\text { Synergistic effect, targeted } \\
\text { delivery into the tumour } \\
\text { cells }\end{array}$ \\
\hline Asthma & Terbutaline sulphate & Subcutaneous injection & $\begin{array}{l}\text { Thin film hydration tech- } \\
\text { nique }\end{array}$ & $\begin{array}{l}\text { Maximizing therapeutic effi- } \\
\text { cacy, reducing undesirable } \\
\text { side effects }\end{array}$ \\
\hline $\begin{array}{l}\text { Non metastatic osteosar- } \\
\text { coma }\end{array}$ & Mifamurtide & I.V infusion & $\begin{array}{l}\text { Non-PEGylated liposome } \\
\text { technology }\end{array}$ & High safety and tolerability \\
\hline Keratitis & Amphotericin B & Ocular & Conventional method & $\begin{array}{l}\text { Effective ocular delivery, } \\
\text { sustained drug release }\end{array}$ \\
\hline Photodynamic therapy & Verteporfin & I.V injection & Conventional technique & $\begin{array}{l}\text { More selective targeted deliv- } \\
\text { ery on CNV }\end{array}$ \\
\hline Pseudomonas aeruginosa & Fluoroquinolones & $\begin{array}{l}\text { Nebulized aerosol (pulmo- } \\
\text { nary) }\end{array}$ & Reverse phase evaporation & $\begin{array}{l}\text { High encapsulation efficiency } \\
\text { and inhibitory concentration }\end{array}$ \\
\hline
\end{tabular}


are present on cancer cells (amino peptidase and integrin's), so the tumour tissue is specific for targeted drug delivery.

Various drugs are formulated as liposomes, i.e. methotrexate, paclitaxel and docetaxel. The anticancer drug release follows two mechanisms into the tumour site viz $\mathrm{pH}$ responsive ( $\mathrm{pH}$ difference between the blood (7.4) and tumour cell (acidic $\mathrm{pH})$ ) and the other is polymer degradation by lysozyme enzyme. Doxorubicin (drug for breast carcinoma) co-loaded with umbelliprenin into liposomes increases toxicity to the tested human breast cancer cell lines and improved uniform size and distribution of liposomes at target site [95].

\subsection{In Vaccines}

The liposomes are used as adjuvants in vaccine delivery by modifying the surface with different molecules such as peptide antigens/virus antigens, to boost the immunity and immunological responses. For example, the membrane proximal external region is an HIV antigen which is on the surface of virion that has low immunogenicity and increases immune responses [96].

\subsection{In Gene Delivery}

Cationic liposomes are most commonly used as gene-carriers. Lofectamine 2000 is a cationic liposome commercially used for gene transfection. Curcumin loaded with STAT3 si-RNA liposomes are used to treat skin cancer, prepared by Bangham method. Liposomes inhibit the growth of B16F10 melanoma cells when compared to free STAT3 si-RNA and free curcumin. Liposomes also deliver the CRISPR or Cas9 gene to treat the genetic disorders and different types of cancers [97].

\subsection{Other Miscellaneous Applications}

The X-ray, magnetic resonance imaging (MRI) and near-IR fluorescence spectroscopy are broadly used for diagnostic imaging. Super paramagnetic liposomes are very efficient as MRI contrast agents. Vitamins such as $\mathrm{C}$ and tocopherol are entrapped in liposomes to increase the thermal structural stability of both vitamins [98]. Carotene was encapsulated in pro-liposomes to protect the natural pigment from degradation [99]. Liposome-entrapped with lemongrass oil (bacteriocinlike substance) shows the antibacterial activity, which avoids spoilage of cheese [100].

\section{Liposomal Formulations Under Clinical Trials}

Various liposomal formulations for numerous applications are under investigation and are on different phases of clinical trials; the ongoing formulations of clinical trials in recent past are listed in Table 5.

\section{Recent Patents on Liposomal Formulations}

Anticancer agents such as doxycycline [DOX], paclitaxel, docetaxel, irinotecan, platinates, vincristine, methotrexate and etoposide of different liposomal formulations are patented in 2019 for their high therapeutic effect on the cancer cells. For instance, Celsion Corp. (NJ, USA) attained patent [US10251901B2] on the thermosensitive DOX liposomes where drug uptake was decreased by the reticuloendothelial system and increased the drug's circulation time. CSIR disclosed a patent US10426728B2:M2 on cationic liposome-encapsulated camptothecin with DOX, which have shown enhanced anticancer efficacy through improvement in the therapeutic index due to synergistic activity of DOX and camptothecin. Tumour-targeted DOX carrier with a heavy chain human ferritin was disclosed by Institute of Biophysics, Chinese Academy of Sciences (PRC), with a patent ID US10195155B2.

Irinotecan, a semi-synthetic camptothecin derivative binds to the DNA topoisomerase-I to inhibit nucleic acid synthesis in the cell cycle (S-phase). An US patent US10456360B2 was issued by Ipsen Biopharm Ltd. (Slough, UK) as irinotecan in formulation as liposomes minimized lysophosphatidylcholine (lyso-PC) formation under storage and prior to patient administration.

Paclitaxel and docetaxel are the most effective anticancer agents used to treat lymphomas and leukaemia, and their formulations as liposomes have a vast improved profile. Syncore Biotechnology Co. Ltd. improved the paclitaxel formulation by freeze-drying paclitaxel liposome formulation and showed much higher polydispersity after reconstitution which is enclosed with patent no. US10413511B2. Shanghai Weiye Biomedical Technology Co. Ltd. reported the patent WO2019218857A1 on docetaxel palmitate liposomal formulation using a chelating agents lecithin and DSPE-PEG2000. Shilpa Medicare Limited patented [WO2019106511A1] for the information on comparison of a pharmaceutical liposomal composition comprised of about $0.8 \% \mathrm{w} / \mathrm{w}$ to about $1 \%$ $\mathrm{w} / \mathrm{w}$ of docetaxel.

Some platinates such as cisplatin and oxaliplatin were recently patented as liposomal formulations. Oncology venture ApS (Denmark) attained a European patent ID EP3342879B1 for cisplatin liposomes with a secretory phospholipase A2 (sPLA2) employed for cancer patients. Mallinckrodt LLC achieved a US patent (US10383823B2 for the zwitterionic liposomes with composite of cisplatin, phosphatidylcholine lipid, PEG-lipid and cholesterol. Liposomal encapsulation with oxaliplatin in an aqueous dispersion holding an external phase of 2-morpholino ethane sulfonic acid divulged by University of Tokushima, 
Table 5 Liposomes under different phases of clinical trials (2020-2021)

\begin{tabular}{|c|c|c|c|c|}
\hline Drug & Disease & Sponsor & Phase & Status \\
\hline Doxorubicin & Hepatocellular carcinoma & Celsion & III & Completed \\
\hline Amikacin & $\begin{array}{l}\text { Nontuberculosis mycobacterial lung } \\
\text { infection }\end{array}$ & Insmed Incorporated & III & Completed \\
\hline Bupivacaine & Post-operative pain & Michael Moncure, MD & IV & Completed \\
\hline Liposomal curcumin & Drug safety & SignPath Pharma & I & Completed \\
\hline Rhenium nano-liposomes & Malignant glioma & Plus Therapeutics & I and II & Recruiting \\
\hline Liposomated iron & $\begin{array}{l}\text { Parentral iron therapy after bariatric } \\
\text { surgery }\end{array}$ & $\begin{array}{l}\text { Hospital Universatari Vall d'Hebron } \\
\text { Research Institute }\end{array}$ & IV & Completed \\
\hline $\begin{array}{l}\text { EphA2-targetting DOPC- } \\
\text { Encapsulated siRNA }\end{array}$ & Solid tumors & M.D. Anderson Cancer Center & I & Active, not recruiting \\
\hline Cabazitaxel & Gastroesophageal Adenocarcinoma & $\begin{array}{l}\text { Weill Medical College of Cornell } \\
\text { University }\end{array}$ & II & Completed \\
\hline Cyclophosphamide & Melanoma & $\begin{array}{l}\text { Sidney Kimmel Comprehensive } \\
\text { Cancer Center }\end{array}$ & I & Complete \\
\hline Dornase alfa & Pulmonary infections & Georgetown University & IV & Completed \\
\hline Azithromycin (T1225) & Eye infections & Laboratoires Thea & I & Completed \\
\hline Influenza vaccination & Influenza & Hadassah Medical Organization & I and II & Completed \\
\hline Cisplatin liposomal & Osteosarcoma Metastatic & Insumed Incorporated & I and II & Completed \\
\hline $\begin{array}{l}\text { Liposomal lactoferrin } \\
\text { SOC therapy }\end{array}$ & COVID-19 & University of Rome Tor Vergata & $\begin{array}{l}\text { II } \\
\text { III }\end{array}$ & Completed \\
\hline LEAF-4L6715 & $\begin{array}{l}\text { COVID-19, sepsis or other causes } \\
\text { acute respiratory distress syndrome }\end{array}$ & $\begin{array}{l}\text { Institut de cancerologie Strasbourg } \\
\text { Europe }\end{array}$ & I and II & Recruiting \\
\hline Hydroxychloroquine & COVID -19 & Taiwan Liposome Company & I & Completed \\
\hline Bioarginina $\mathrm{C}$ & $\begin{array}{l}\text { Fatigue syndrome Chronic inflamma- } \\
\text { tion (post COVID) }\end{array}$ & University of Milan & Not applicable & Recruiting \\
\hline $\begin{array}{l}\text { SpFN COVID-19 vac- } \\
\text { cine, QS21 (ALFQ) } \\
\text { adjuvant }\end{array}$ & SARS-CoV-2 infection & $\begin{array}{l}\text { U.S. Army Medical Research and } \\
\text { Development Command }\end{array}$ & I & Active, not recruiting \\
\hline
\end{tabular}

Taiho Pharmaceutical Co. Ltd. (Japan), with a patent ID US10383822B2.

Vinca alkaloids (vincristine, vinblastine and vinorelbine) are the antimitotic agents that act by disrupting the microtubule assembly through interaction with tubulin with an eventual arrest of metaphase. A patent granted recently by Arbutus Biopharm with ID EP2922529B1 for vincristine encapsulation in liposome for therapeutic applications. The US10188728B2 patent issued for Temple University (PA, USA) for their elaborate work on breast cancer treatment through immunoliposome formulation through targeted and non-targeted delivery strategy employing vinblastine, bevacizumab and verapamil with a target on Her-2/neu.

A US patent US10307491B2:2019 was granted for an antibiotic mitoxantrone as liposomal formulation by University of Michigan for cancer treatment through mitoxantrone encapsulation in liposomal formulation with one or more cationic lipids and hyaluronic acid.

Some of the other recently patented liposomal formulations in past 3 years (2019-2021) are listed in Table 6.

\section{Conclusion}

Liposome-based drug delivery systems are the versatile nano-drug delivery tools that effectively deliver different drugs to specific target sites. Liposomes are used as carriers to increase therapeutic index of several drugs. Researchers has expanded their research on liposomes due to their unique characteristics such as non-toxicity, biodegradability, targeted drug delivery, biocompatibility, non-immunogenicity, and reduced toxicity by improvization of preparation techniques and drug-loading methods. However, most of them are limited to laboratory scale. For economical ease and stability improvement of liposomes, various processes are under development. In liposome preparations, SCF technology draws significant attention due to solvent free and high drug encapsulation efficiency of liposomes. Based on the current liposomal research, novel methods with novel applications and repurposing of drugs are on boon making the efficient targeted delivery with reduced toxicity. This review highlights the recent developments of liposomal formulations with novel formulation methodologies that are easy scalable at industrial level with description their pros and 
Table 6 Recent patents on liposome formulations (2019-2021)

\begin{tabular}{lll}
\hline Title with inventors & Patent ID & Innovation for patent \\
& Year & \\
\hline
\end{tabular}

Controlled drug release liposome compositions and methods thereof

Pei Kan, Yun-Long Tseng, Han-Chun Ou, Chun-yen Lai

Composition comprising an onion extract and liposomes Peter Boderke, Martina Heberer, Petra Scheppler

Liposome composition and method for producing same Makoto Ono, Kohei Ono, Takeshi Matsumoto, Mikinaga Mori

Liposome Containing Compositions and Their Use in Personal Care and Food Products

Richard Rigg, lmani Rigg

Tailored liposomes for the treatment of bacterial infections

Eduard Babiychuk, Annette Draeger

Remote loading of sparingly water-soluble drugs into liposomes

Mark E. Hayes, Charles O. Noble, Francis C. Szoka, Jr

Liposome composition for use in peritoneal dialysis

Jean-Christophe Leroux, Vincent Forster

Methods and devices for liposome preparation by centrifugation

Oleg Guryev, Tatyana Chernenko, Marybeth Sharkey

Formulation comprising liposomes

Hiroshi Ishihara, Katsura Hata, Hiroki Muto, Geoff Hird

Liposomes comprising polymer-conjugated lipids and related uses

Saul Yedgar

Liposomes with ginsenoside as membrane material and preparations and use thereof

Chong Li, Yahua Wang, Huaxing Zhan

Bi-directionally crosslinked liposomes and method of making same

Kimberly Kam, Zhan Wang, Stephen Morton

Method for preparing liposome frozen powder capable of efficiently retaining its bilayer structure

Pahn Shick Chang, Kyung Min Park, Eun Hye Yang, Ho Sup Jung

Composition for preventing or treating ischemic diseases, containing liposomes in which VEGF-derived peptides are supported

Hwan Jeong

Microfluidic liposome synthesis, purification and active drug loading

Renee Hood, Donald Lad DeVoe

Combinational liposome compositions for cancer therapy Jun Yang, Stephen H. Wu, Cliff J. Herman
US11147881 Consisting of at least one liposome, or poly/mono valent 2021 counterion donor or a pharmaceutically acceptable salt, and an amphipathic therapeutic agent. This relates to methods of inhibiting cancer cell growth with reduced toxicity with the mentioned composition

US10967036 Onion extract encapsulated liposomes, for treatment/preventing 2021 scars

US10898435 Innovative method for long-term stability, and a high release rate 2021 of a drug controlled by an inner hyper-osmotic water phase

US10702475 A liposomal composition of polyglyceryl-10 diacyl surfactant 2020 and a water soluble cation in interior aqueous medium to retain the liposome on a substrate for many rinse treatments

US10744089 Liposomes of defined lipid monolayers/bilayers composition for 2020 the prevention of bacterial (Staphylococcus aureus or Streptococcus pneumonia) infections

US10722467 For a scalable process, where lipid composition and remote 2020 loading agent are optimized, resulting in high drug-to-lipid ratios and prolonged drug retention for less soluble drugs $(<2 \mathrm{mg} / \mathrm{mL})$ during administration to a subject

US10596114 Liposomal composition for peritoneal dialysis in patients suf2020 fering from toxicopathies and for a method of administrating therapeutically effective amount into the patient's peritoneal space

US10556216 Methods that impart centrifugal force to a suspension to allow 2020 liposomes through a porous membrane for production of liposomes

US10765633 A liposomal formulation containing 0.7 to $3.0 \mathrm{~mol} \%$ of eritoran $2020 \quad$ or a pharmaceutically acceptable salt and 0.5 to $3.0 \mathrm{~mol} \%$ of a PEGylated phospholipid

US10624851 A method of delivering a nucleic acid when encapsulated in a $2020 \quad$ liposome

A method for performing diagnostic imaging with an encapsulated diagnostic agent in a mixed liposome

Methods for treating pathological mixed liposome is administered to a subject

US10639276 The liposomes have a membrane comprising lipids and a ginse2020 noside

US10842746 Bi-directionally crosslinked liposomes with reactive hydrophilic 2020 and hydrophobic groups

US10660853 For method using solvents (ethyl acetate and n-hexane) followed 2020 by preparation of frozen powder by inserting in isopropyl alcohol, ethanol and/or methanol, followed by lyophilization, for use in food industry with no toxic chloroform

US10617641 A novel method for treating ischemic diseases with loaded vas2020 cular endothelial growth factor (VEGF) -derived peptides

US10434065 Microfluidic methods and systems for large production of 2019 liposomes

US10213385 Method for delivery of active ingredient to a subject employing 2019 multi-component liposomal systems 
cons in detail. It is the need of the hour to put forth efforts to enhance encapsulation efficiency, stability, sterility and scaling of liposomes considering the thermo-sensitive (proteins and other biomolecules) materials to be incorporated for drug delivery, fortifying the use of biocompatible organic solvents (ethanol, ethyl acetate), etc. In addition to novel methodologies for liposomes, commercially available formulations, ongoing clinical trials and patents in recent past are detailed, which is distinctive in this review. Therefore, this review can hopefully provide a way for future liposomebased therapeutics as the delivery options for natural/synthetic/semi-synthetic anticancer and other compounds by encapsulation and can stock gradual advancement in the delivery with targeted drug and method-specific delivery requirements in encapsulated liposomes.

\section{Funding None.}

\section{Declarations}

\section{Conflict of Interest None.}

Research Involving Humans and Animals Statement None.

Informed Consent Additional informed consent was obtained from all individuals for whom identifying information is included in this article.

\section{References}

1. Harendra, S., \& Vipulanandan, C. (2006). Production and Characterization of Liposome Systems for Pharmaceutical Applications, Vipulanandan Center for Innovative Grouting Material and Technology (CIGMAT), Department of Civil and Environmental Engineering University of Houston: Houston, pp. 77202-4003

2. Marchianoa, V., Matosb, M., Pertierraa, E. S., Gutiérrezb, G., \& Blanco-Lópeza, M. C. (2020). Vesicles as antibiotic carrier: State of art. International Journal of Pharmaceutics, 585, 119478.

3. Cha, Y., Son, B., \& Ryu, S. (2019). Effective removal of staphylococcal biofilms on various food contact surfaces by Staphylococcus aureus phage endolysin LysCSA13. Food Microbiology, 84,103245

4. Chunyan, L., Zhang, L., Zhu, W., Guo, R., Sun, H., Chen, X., \& Deng, N. (2020). Barriers and stratagies of Cationic Liposomes for Cancer Gene Therapy. Molecular Therapy-Methods \& Clinical Development, 18, 751-764.

5. Rodrigues, B. S., Kanekiyo, T., \& Singh, J. (2020). In vitro and in vivo characterization of CPP and transferrin modified liposomes encapsulating pDNA. Nanomedicine: Nanotechnology, Biology and Medicine, 28, 102225.

6. Bezerra, C. F., Alencar Junior, J. G., Honorato, R. L., \& Santos, A. T. L. (2020). Antifungal activity of furnesol incorporated in liposomes and associated with fluconazole. Chemistry and Physics of Lipids, 233, 104987.

7. Oliveira, J. K., Nakamura, T. U., Correa, A. G., Petrilli, R., Vianna Lopez, R. F., Nakamura, C. V., \& Velty, R. A. (2020). Liposome-based nanocarrier loaded with a new quinoxaline derivative for the treatment of cutaneous leishmaniasis. Materials Science and Engineeting: C, 110, 110720.

8. Zhang, Y., Wei, H., Du, Y., Ying, D., Zhao, C., Zhang, Y., Zhang, H., Yin, L., \& Xinsong, L. (2020). Dimeric artesunate phospholipid-conjugated liposomes as promising anti-inflammatory therapy for rheumatoid arthritis. International Journal of Pharmaceutics, 576, 119178.

9. Zhang, Z. J., \& Michniak-Kohn, B. (2020). Flavosomes, novel deformable liposomes for the co-delivery of anti-inflammatory compounds to skin. International Journal of Pharmaceutics, 585,119500 .

10. Bai, L., Fei, W. D., Ying, Y. G., Miao, H., Du, F., Zhang, W. Y., Yang, L. L., \& Liu, Y. J. (2020). Liposomes encapsulated iridium (III) polypyridyl complexes enhance anticancer activity in vitro and in vivo. Journal of Inorganic Biochemistry, 205, 111014.

11. Li, Y., Tan, X., Liu, X., Liu, L., Fang, Y., Rao, R., Yuanyuan, R., Yang, X., \& Liu, W. (2020). Enhanced anticancer effect of doxorubicin by TPGS-coated liposomes with Bcl-2 siRNA-corona for dual suppression of drug resistance. Asian Journal of Pharmaceutical Sciences, 15(5), 646-660.

12. Bangham, A. D., Standish, M. M., \& Watkins, J. C. (1965). Diffusion of univalent ions across the lamellae of swollen phospholipids. Journal of Molecular Biology, 13(1), 238-252.

13. Morgan, J. R., Williams, L. A., \& Haward, C. B. (1985). Technetium-labelled liposome imaging for deep-seated infection. British Journal of Radiology, 58, 35-39.

14. Aghdam, M. A., Bagheri, R., Mosafer, J., Baradaran, B., Hashemzaei, M., Baghbanzadeh, A., de la Guardia, M., \& Mokhtarzadeh, A. (2019). Recent advances on thermosensitive and $\mathrm{pH}$-sensitive liposomes employed in controlled release. Journal of Controlled Release, 315, 1-22.

15. Akbarzadeh, A., Rezaei-Sadabady, R., Davaran, S., Joo, S. W., Zarghami, N., Hanifehpour, S. Y., Samiei, M., Kouhi, M., \& Nejati-Koshki, K. (2013). Liposome: Classification, preparation, and applications. Nanoscale Research Letters., 8(1), 102.

16. Torchilin, V. P. (2005). Recent advances with liposomes as pharmaceutical carriers. Nature Reviews Drug Discovery, 4(2), 145-160.

17. Kim, E.-M., \& Jeong, H. (2021). Liposomes: Biomedical Applications. Chonnam Medical Journal, 57(1), 27-35.

18. Guimarães, D., Cavaco-Paulo, A., \& Nogueira, E. (2021). Design of liposomes as drug delivery system for therapeutic applications. International Journal of Pharmaceutics., 601, 120571.

19. Shah, S., Dhawan, V., Holm, R., Nagarsenker, M. S., \& Perrie, Y. (2020). Liposomes: Advancements and innovation in the manufacturing process. Advanced Drug Delivery Reviews., 2020(154-155), 102-122.

20. Woodle, M. C. (1995). Sterically stabilized liposome therapeutics. Advanced Drug Delivery Reviews, 16(2-3), 249-265.

21. Paltauf, F., \& Hermetter, A. (1990). Phospholipids - Natural, Semisynthetic, Synthetic. In I. Hanin \& G. Pepeu (Eds.), Phospholipids: Biochemical, Pharmaceutical, and Analytical Considerations (pp. 1-12). Springer.

22. Nagayasu, A., Uchiyama, K., \& Kiwada, H. (1999). The size of liposomes: A factor which effects their targeting efficiency to tumors and therapeutic activity of liposomal antitumor drugs. Advanced Drug Delivery Reviews., 40, 75-87.

23. Li, J., Wang, X., Zhang, T., Wang, C., Huang, Z., Luo, X., \& Deng, Y. (2015). A review on phospholipids and their main applications in drug delivery systems. Asian Journal of Pharmaceutical Sciences, 10(2), 81-98.

24. Gensure, H., Rebekah, M. L., Zeidel, \& Hill, W. G. (2006). Lipid raft components cholesterol and sphingomyelin increase $\mathrm{H}+$ / $\mathrm{OH}-$ permeability of phosphatidylcholine membranes. Biochemical Journal, 398(3), 485-495. 
25. Spec, I. S. S., Waterhouse, D. N., Madden, T. D., Cullis, P. R., Bally, M. B., Mayer, L. D., \& Webb, M. S. (2005). In: Liposomes (pp. 40-57). Methods in Enzymology, Elsevier Academic Press.

26. Mozafari, M Reza. (2007). Nanomaterials and Nano systems for Biomedical Applications (pp. 83-98). Springer.

27. Sackmann, E. (1994). Membrane bending energy concept of vesicle-and cell-shapes and shape-transitions. FEBS Letters, 346(1), $3-16$.

28. Suntres, Z. E.(2011). Liposomal Antioxidants for Protection against Oxidant-Induced Damage. Journal of Toxicology, 1-16.

29. Maruyama, K., Ishida, O., Kasaoka, S., Takizawa, T., Utoguchi, N., \& Shinohara, A. (2004). Intracellular targeting of sodium mercaptoundecahydrododecaborate (BSH) to solid tumors by transferrin-PEG liposomes, for boron neutron-capture therapy (BNCT). Journal of Controlled Release, 98(2), 195-207.

30. Lamichhane, N., Udayakumar, T. S., D’Souza, W. D., Simone, C. B., Raghavan, S. R., Polf, J., \& Mahmood, J. (2018). Liposomes: Clinical Applications and Potential for image-Guided Drug Delivery. Molecules, 23(2), 288.

31. Cagdas, M., Sezer, A. D., \& Bucak, S. (2014). Liposomes as potential drug carrier systems for drug delivery, application of nanotechnology in drug delivery. Ali Demir Sezer, IntechOpen.

32. Knop, R., \& Hoogenboom, D. (2010). U.S. Schubert Fischer Poly. (ethylene glycol) in drug delivery: pros and cons as well as potential alternatives. Angewandte Chemie International Edition, 49(36), 6288-6388.

33. Taira, M. C., Chairamoni, N. S., Pecuch, K. M., \& AlonsoRomanowski, S. (2004). Stability of liposomal formulations in physiological conditions for oral drug delivery. Drug Delivery, $11,123-128$

34. Sagahara, S., Kajiki, M., Kuriyama, H., \& Kobayashi, T. (2006). Complete regression of Xenog rafted human carcinomas by a paclitaxel-carboxymethyl dextran conjugate (AZ10992). Journal Controlled Release, 117, 40-50.

35. Mozafari, M. R., \& Mortazavi, M. S. (2005). Nanoliposomes: From Fundamentals to Recent Developments. Trafford Publishing Co Ltd.

36. Lasic, D. D. (1993). Kinetic and thermodynamic effects in the formulation of amphiphilic colloidal particles. Journal of Liposome Research., 3(2), 257-273.

37. Gref, R., Minamitake, Y., Peracchia, M. Y., Trubetskoy, V., Torchilin, V., \& Langer, R. (1994). Biodegradable long-circulating polymeric nanospheres. Science, 18, 1600-1603.

38. Metselaar, J. M., Bruin, P., De Boer, L. W., De Vringer, T., Snel, C., Oussoren, C., Wauben, M. H., Crommelin, D. J., Storm, G., \& Hennink, W. E. (2003). A novel family of L-amino acid-based biodegradable polymer-lipid conjugates for the development of long-circulating liposomes with effective drug-targeting capacity. Bioconjugate Chemistry, 14(6), 1156-1164.

39. Krieg, A. M. (2001). From bugs to drugs: Therapeutic immunomodulation with oligodeoxynucleotides containing $\mathrm{CpG}$ sequences from bacterial DNA. Antisense Nucleic Acid Drug Development, 11(3), 181-188.

40. Mozafari, M. R., Flanagan, J., Matia-Merino, L., Awati, A., Omri, A., Suntres, Z. E., \& Singh, H. (2006). Recent trends in the lipid-based nanoencapsulation of antioxidants and their role in foods. Journal of the Science of Food and Agriculture., 86(13), 2038-2045.

41. Garti, N. (2008). Delivery and controlled release of bioactives in foods and nutraceuticals. Woodhead Publishing Limited.

42. Zarif, L., Graybill, J. R., Perlin, D., \& Mannino, R. J. (2000). Cochleates: New lipid based drug delivery system. Journal of Liposome Research, 10(4), 523-538.

43. Zarif, L. (2002). Elongated supramolecular assemblies in drug delivery. Journal Controlled Release., 81(1-2), 7-23.
44. Tardi, C., Drechsler, M., Bauer, K. H., \& Brandl, M. (2001). Steam sterilisation of vesicular phospholipid gels. International Journal of Pharmaceutics, 217(1-2), 161-172.

45. Rafe, M. R., \& Ahmed, Z. (2017). Liposomal drug delivery systems have opened a new window in pharmaceutical sciences: A literature-based review. Asian Journal of Pharmaceutics, 11(4), 250-254.

46. Bulbake, U. Doppalapudi, S. Kommineni, N. Khan, W. Liposomal Formulations in Clinical Use: An Updated Review. Pharmaceutics, 2017; 9.

47. Bangham, A. D., Standish, M. M., \& Weissmann, G. (1965). The action of steroids and streptolysin $\mathrm{S}$ on the permeability of phospholipid structures to cations. Journal of Molecular Biology, 13(1), 253-259.

48. Zhang, H. (2017). Thin film hydration followed by Extrusion Method for Liposome Preparation. Methods in Molecular Biology, 1522, 17-22.

49. Sharma, N., \& Verma, S. (2017). Current and future prospective of liposomes as drug delivery vehicles for the effective treatment of cancer. International journal of Green Pharmacy, 11(3), 8377.

50. Batzri, S., \& Korn, E. D. (1973). Single bilayer liposomes prepared without sonication. Biochimica et Biophysica Acta (BBA) - Biomembranes, 298(4), 1015-1019.

51. Deamer, D. W. (1978). Preparation and properties of ether injection liposomes. Annals of the New York Academy of Sciences, 308, 250-258.

52. Bnyan, R. Cesarini, L. Khan, I. Roberts, M., \& Ehtezazi, T. (2020). The effect of ethanol evaporation on the properties of inkjet produced liposomes. DARU Journal of Pharmaceutical Sciences, 28(5).

53. Szoka, F., \& Papahadjopoulos, D. (1978). Procedure for preparation of liposomes with large internal aqueous space and high capture by reverse-phase evaporation. Proceedings of the National Academy of Sciences of the USA, 75(9), 4194-4198.

54. Handa, T., Naito, S., Hiramatsu, M., \& Tsuboi, M. (2006). Thermal $\mathrm{SiO}$ and $\mathrm{H} 13 \mathrm{CO}+$ line observations of the dense molecular cloud G0.11-0.11 in the Galactic Center Region. Astrophys $J$, 636, 261-266.

55. Brunner, J., Skrabal, P., \& Hauser, H. (1976). Single bilayer vesicles prepared without sonication: physico chemical properties. Biochimica et Biophysica Acta (BBA) - Biomembranes, 455(2), 322-331.

56. Shaheen, S. M., Shakil Ahmed, F. R., Hossen, M. N., Ahmed, M., Amran, M. S., \& UI-Islam, M. A. (2006). Liposomes as a carrier for the advanced drug delivery. Pak J Biol Sci, 9(6), 1181-1191.

57. Jahn, A., Vreeland, W. N., Devoe, D. L., Locascio, L. E., \& Gaitan, M. (2007). Microfluidic directed formation of liposomes of controlled size. Langmuir, 23(11), 6289-6293.

58. Yu, Bo., Lee, J Robert, \& Lee, L James. (2009). Microfluidic Methods for Production of Liposomes. Methods in Enzymology., 465, 129-141.

59. Mozafari, M. R. (2005). Liposomes: An overview of manufacturing techniques. Cellular \& Molecular Biology Letters., 10, 711-719.

60. Nkanga, C. I., \& Krause, R. W. M. (2019). Encapsulation of Isoniazid-conjugated Phthalocyanine-In-Cyclodextrin-InLiposomes Using Heating Method. Scientific Reports, 9, 11485.

61. Jahadi, M., Darani, K. K., Ehsani, M. R., Mozafari, M. R., Saboury, A. A., \& Pourhosseini, P. S. (2015). The Encapsulation of Flavourzyme in Nano liposome by heating method. Journal of Food Science and Technology, 52(4), 2063-2072.

62. Nidhal, K. M., \& Athmar, D. H. (2012). Preparation and evaluation of salbutamol liposomal suspension using chloroform film method. Mustansiriya Medical Journal, 11(2), 39-44.

63. Maalej, C. J., Diab, R., Andrieu, V., Elaissari, A., \& Fessi, H. (2010). Ethanol injection method for hydrophilic and 
lipophilic drug-loaded liposome preparation. Journal of Liposome Research, 20(3), 228-243.

64. Jia, M., Deng, C., Luo, J., Zhang, P., Sun, X., Zhang, Z., \& Gong, T. (2018). A novel dexamethasone loaded liposome alleviates rheumatoid arthritis in rats. International Journal of Pharmaceutics, 540(1-2), 57-64.

65. Laouini, A. Maalej, C. J. Gandoura-Sfar, S. Charcosset, C., \& Fessi, H. (2012). Spironolactone-Loaded liposomes produced using a membrane contractor method: An improvement of the Ethanol injection technique. Progress in Colloids and Polymer Science, 139.

66. Hirsch, M., Ziroli, V., Helm, M., \& Massing, U. (2009). Preparation of small amounts of sterile siRNA - liposomes with high entrapping efficiency by dual asymmetric centrifugation (DAC). Journal of Controlled Release., 135(1), 80-88.

67. Fei, X., Heyang, J., Yaping, Z., \& Xinqiu, G. (2011). Supercritical Antisolvent-based Technology for Preparation of Vitamin D-3 Proliposome and Its Characteristics. Chinese Journal of Chemical Engineering, 19(6), 1039-1046.

68. Maja, L., Zeljko, K., \& Mateja, P. (2020). Sustainable technologies for liposome preparation. The Journal of Supercritical Fluids, 165, 1049-1084.

69. Imura, T., Gotoh, T., Otake, K., Yoda, S., Takebayashi, Y., Yokoyama, S., Takebayashi, H., Sakai, H., Yuasa, M., \& Abe, M. (2003). Control of physicochemical properties of liposomes using a supercritical reverse phase evaporation method. Langmuir, 19, 2021-2025.

70. Zhao, L., \& Temelli, F. (2017). Preparation of anthocyaninloaded liposomes using an improved supercritical carbon dioxide method. Innovative Food Science and Emerging Technologies, 39, 119-128.

71. Varona, S., Martin, A., \& Cocero, M. J. (2011). Liposomal Incorporation of Lavandin Essential Oil by a Thin-Film Hydration Method and by Particles from Gas-Saturated Solutions. Industrial and Engineering Chemistry Research., 50, 2088-2097.

72. Machado, A. R., \& Cercueira, A. M. (2019). Liposomes loaded with phenolic extracts of spirulina LEB-18, physicochemical characterization and behavior under simulated gastrointestinal conditions. Food research international, 120, 653-667.

73. Pauli, G., Tang, W. L., \& Li, S. D. (2019). Development and Characterization of the Solvent-Assisted Active Loading Technology (SALT) for Liposomal Loading of Poorly Water-Soluble Compounds. Pharmaceutics, 11, 465.

74. Lara, L. A., Avila, E. M., Gutierrez, M. A. L., Alvarez, E. O., \& Olive, K. I. (2020). Radiolabeled liposomes and lipoproteins as lipidic nanoparticles for imaging and therapy. Chemistry and Physics of Lipids, 230, 104934.

75. Bagheri, H., Mansoori, G. A., \& Hashemipour, H. (2018). A novel approach to predict drugs solubility in supercritical solvents for RESS process using various cubic EoS-mixing rule. Journal of Molecular Liquids, 261, 174-188.

76. Yen, T. T. H. Dan, L. N. Hoang, L. D. Tung, B. T., \& Minh Hue, P. T. (2019). Preparation and characterization of freeze dried liposomes loaded with Amphotericin B. Current Drug Therapy, 14(1).

77. Trucillo, P., Campardelli, R., Scognamiglio, M., \& Reverchon, E. (2019). Control of liposomes diameter at micrometric and nanometric level using a supercritical assisted technique. Journal of CO2 Utilization, 32, 119-127.

78. Chakravarty, P., Famili, A., Nagapudi, K., \& Al-Sayah, M. A. (2019). Using supercritical fluid technology as a green alternative during the preparation of drug delivery systems. Pharmaceutics, 11,629 .

79. Primozic, M., Colnik, M., Knez, Z., \& Leitgeb, M. (2019). Advantages and disadvantages of using $\mathrm{SC} \mathrm{CO} 2$ for enzyme release from halophilic fungi. Journal of Supercritical Fluids, 143, 286-293.

80. Pasquali, I., \& Bettini, R. (2008). Are pharmaceutics really going supercritical? International Journal of Pharmaceutics., 364, 176-187.

81. Pawar, N., Agrawal, S., \& Methekar, R. (2019). Continuous Antisolvent Crystallization of $\alpha$-Lactose Monohydrate: Impact of Process Parameters, Kinetic Estimation, and Dynamic Analysis. Organic Process Research \& Development, 23(11), 2394-2404.

82. Otake, K., Shimomura, T., Goto, T., Imura, T., Furuya, T., Yoda, S., Takebayashi, Y., Sakai, H., \& Abe, M. (2006). Preparation of Liposomes Using an Improved Supercritical Reverse Phase Evaporation Method. Langmuir, 22(6), 2543-2550.

83. Huang, Z., Li, X., Zhang, T., Song, Y., She, Z., Li, J., \& Deng, Y. (2014). Progress involving new techniques for liposome preparation. Asian Journal of Pharmaceutical Sciences, 9(4), 176-182.

84. Trucillo, P., Campardelli, R., \& Reverchon, E. (2019). Antioxidant loaded emulsions entrapped in liposomes produced using a supercritical assisted technique. The Journal of Supercritical Fluids, 154, 10462-10466.

85. Trucillo, P., Campardelli, R., \& Reverchon, E. (2017). Supercritical $\mathrm{CO} 2$ assisted liposomes formation: Optimization of the lipidic layer for an efficient hydrophilic drug loading. Journal of CO2 Utilization, 18, 181-188.

86. Spyratou, E., Mourelatou, E. A., Makropoulou, M., \& Demetzos, C. (2009). Atomic force microscopy: A tool to study the structure, dynamics and stability of liposomal drug delivery systems. Expert Opinion on Drug Delivery, 6(3), 305-317.

87. Mehdi Hasan, Md., Hasan, M., Mondal, J. C., Hasan, M. A., Talukder, S., \& Rashid, H. A. (2017). Liposomes: An advance tools for novel drug delivery system. The Pharma Innovation Journal, 6(11), 304-311.

88. Bokrova, J. Marova, I. Matouskova, P. Pavelkova, R. Fabrication of novel PHB-liposome nanoparticles and study on their toxicity in vitro. Journal of Nanoparticle Research, 2019; 21(3).

89. Smith, M. C., Crist, R. M., Clogston, J. D., \& McNeil, S. E. (2017). Zeta potential: A case study of cationic, anionic and neutral liposomes. Analytical and bioanalytical chemistry, 409(24), $5779-5787$.

90. Ong, S. G. M., Ming, L. C., \& Lee, K. S. (2016). Influence of the encapsulation efficiency and size of liposome on the oral bioavailability of griseofulvin-loaded liposomes. Pharmaceutics, 8(3), 25.

91. Moghimipour, E., \& Handali, S. (2012). Utilization of thin film method for preparation of celecoxib loaded liposomes. Advanced pharmaceutical bulletin, 2(1), 93-98.

92. Shamshiri, M. K., Jaafari, M. R., \& Badiee, A. (2021). Preparation of liposomes containing IFN-gamma and their potentials in cancer immunotherapy: In vitro and in vivo studies in a colon cancer mouse model. Life Sciences, 264, 11860-11865.

93. Amiri, M., Gholami, T., Amiri, O., Pardakhti, A., Ahmadi, M., Akbari, A., Amanatfard, A., \& Niasari, M. S. (2020). The magnetic inorganic-organic nanocomposite based on $\mathrm{ZnFe} 2 \mathrm{O} 4$ Imatinib-liposome for biomedical applications, in vivo and in vitro study. Journal of Alloys and Compounds, 849, 15660-15664.

94. Feghhi, M. Makhmalzadeh, B.S. Farrahi, F. Akmali, M. Hasanvand, N. Anti-microbial effect and in vivo Ocular Delivery of Ciprofloxacin-loaded Liposome through Rabbit's Eye. Current Eye Research, 2020; 45(10).

95. Gkionis, L., Campbell, R. A., Aojula, H., Harris, L. K., \& Tirella, A. (2020). Manufacturing drug co-loaded liposomal formulations targeting breast cancer: Influence of preparative method on liposomes characteristics and in vitro toxicity. International Journal of Pharmaceutics, 30, 11992-11996. 
96. Wang, N., Chen, M., \& Wang, T. (2019). Liposomes used as a vaccine adjuvant-delivery system: From basics to clinical immunization. Journal of Controlled Release, 303(10), 130-150.

97. Li, L., Hu, L. S., \& Chen, X. (2018). Non-viral delivery systems for CRISPR/Cas9-based genome editing: Challenges and opportunities. Biomaterials, 171, 207-218.

98. Marsanasco, M., Piotrkowski, B., Calabr'o, V., Alonso, S. D. V., \& Chiaramoni, N. S. (2015). Bioactive constituents in liposomes incorporated in orange juice as new functional food: Thermal stability, rheological and organoleptic properties. Journal of Food Science \& Technology, 52, 7828-7838.

99. Toniazzo, T., Berbel, I. F., Cho, S., F'avaro-Trindade, C. S., Moraes, I. C. F., \& Pinho, S. C. (2014). $\beta$-carotene-loaded liposome dispersions stabilized with xanthan and guar gums: Physico-chemical stability and feasibility of application in yogurt. LWT-Food Science and Technology, 59, 1265-1273.

100. Cui, H., Wu, J., \& Lin, L. (2016). Inhibitory effect of liposomeentrapped lemongrass oil on the growth of Listeria monocytogenes in cheese. Journal of Dairy Science, 99, 6097-6104.

Publisher's Note Springer Nature remains neutral with regard to jurisdictional claims in published maps and institutional affiliations. 